\title{
Primary Intramedullary Frontal Bone Osteoblastoma: A Case Report
}

\author{
Senai Goitom Sereke, MBChB, MMed (Radiology) ${ }^{1 *}$ and Felix Bongomin, MBChB, MSc ${ }^{2,3}$ \\ ${ }^{1}$ Department of Radiology and Radiotherapy, School of Medicine, Makerere University College of Health \\ Sciences, Kampala, Uganda \\ ${ }^{2}$ Department of Medicine, School of Medicine, Makerere University College of Health Sciences, Kampala, \\ Uganda
}

${ }^{3}$ Department of Medical Microbiology and Immunology, Faculty of Medicine, Gulu University, Gulu, Uganda

*Corresponding author: Senai Goitom Sereke, Department of Radiology and Radiotherapy, School of Medicine, Makerere University College of Health Sciences, Kampala, Uganda, Tel: +256-786-271-349

\begin{abstract}
Introduction: Osteoblastoma is a rare osteoid tissue forming tumor commonly affecting the posterior element of the spine. Intramedullary osteoblastoma of the calvarium is extremely rare. Osteoblastoma rarely occurs in the first decade of life. In this report we describe osteoblastoma of a very uncommon location in an 8-years-old male.

Case presentation: An 8-year-old male presented with a 2-year history of progressive painless swelling of the left forehead. There was no prior history of trauma to the head. Head computed tomography (CT) scan demonstrated an intramedullary oval shaped osseous lesion in the left frontal bone. Core biopsy histopathology revealed cranial osteoblastoma. Total resection of the mass was done.

Conclusion: For calvarial osteoblastoma, CT scan plays an important role in the diagnosis and differentiation from other cranial osseous tumors, yet histopathology defines the final diagnosis.
\end{abstract}

\section{Keywords}

Frontal bone, Osteoblastoma, Intramedullary, CT scan findings

\section{Abbreviations \\ CT: Computed tomography}

\section{Introduction}

Osteoblastoma, also known as giant osteoid osteo$\mathrm{ma}$, is a rare entity comprisingless than $1 \%$ of all bone neoplasms [1]. Lesions widely vary in size, ranging from
2 to $10 \mathrm{~cm}$ with an average size of $4 \mathrm{~cm}$ at diagnosis [2]. It commonly affects the spine, particularly the posterior vertebral elements and the sacrum [3]. If it arises in the head, it typically affects the mandible or maxillofacial bones and, only in about $2-4 \%$ of the cases where the tumor derived from the cranial bones [4]. The temporal bone is commonly involved followed by frontal and ethmoid bones [5]. Osteoblastoma has predilection for males and mostly occur in those aged $10-30$ years [6]. The lesion is often well-demarcated, with no infiltration of adjacent bone, but bone remodeling can occur depending on the size and site of the lesion. Calvarial osteoblastoma present as widened diploe with resultant thinning of the inner and/or outer tables and varying degree of calcifications [2,7]. Computed tomography (CT) scan provides information regarding bone expansion and destruction, lesion margins, host bone response, and tumor matrix [8]. Herein, we describe a rare case of primary skull bone osteoblastoma. Osteoblastoma rarely occurs in the first decade of life. In this report we describe a case of osteoblastoma in an 8-years-old male and in uncommon location that's the frontal bone.

\section{Case Presentation}

An 8-year-old male presented with a 2-year history of a progressive yet painless left forehead swelling. Mother reported that the swelling was very small initially and grew in size with time. There was no history of trauma.

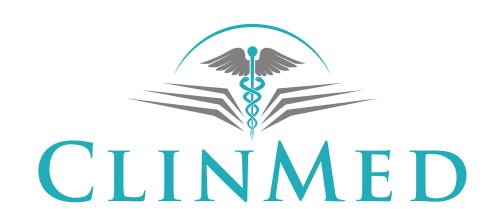

INTERNATIONAL LIBRARY
Citation: Sereke SG, Bongomin F(2021) Primary Intramedullary Frontal Bone Osteoblastoma: A Case Report. Neurosurg Cases Rev 4:055. doi.org/10.23937/2643-4474/1710055

Accepted: January 14, 2021; Published: January 16, 2021

Copyright: (c) 2020 Sereke SG, et al. This is an open-access article distributed under the terms of the Creative Commons Attribution License, which permits unrestricted use, distribution, and reproduction in any medium, provided the original author and source are credited. 


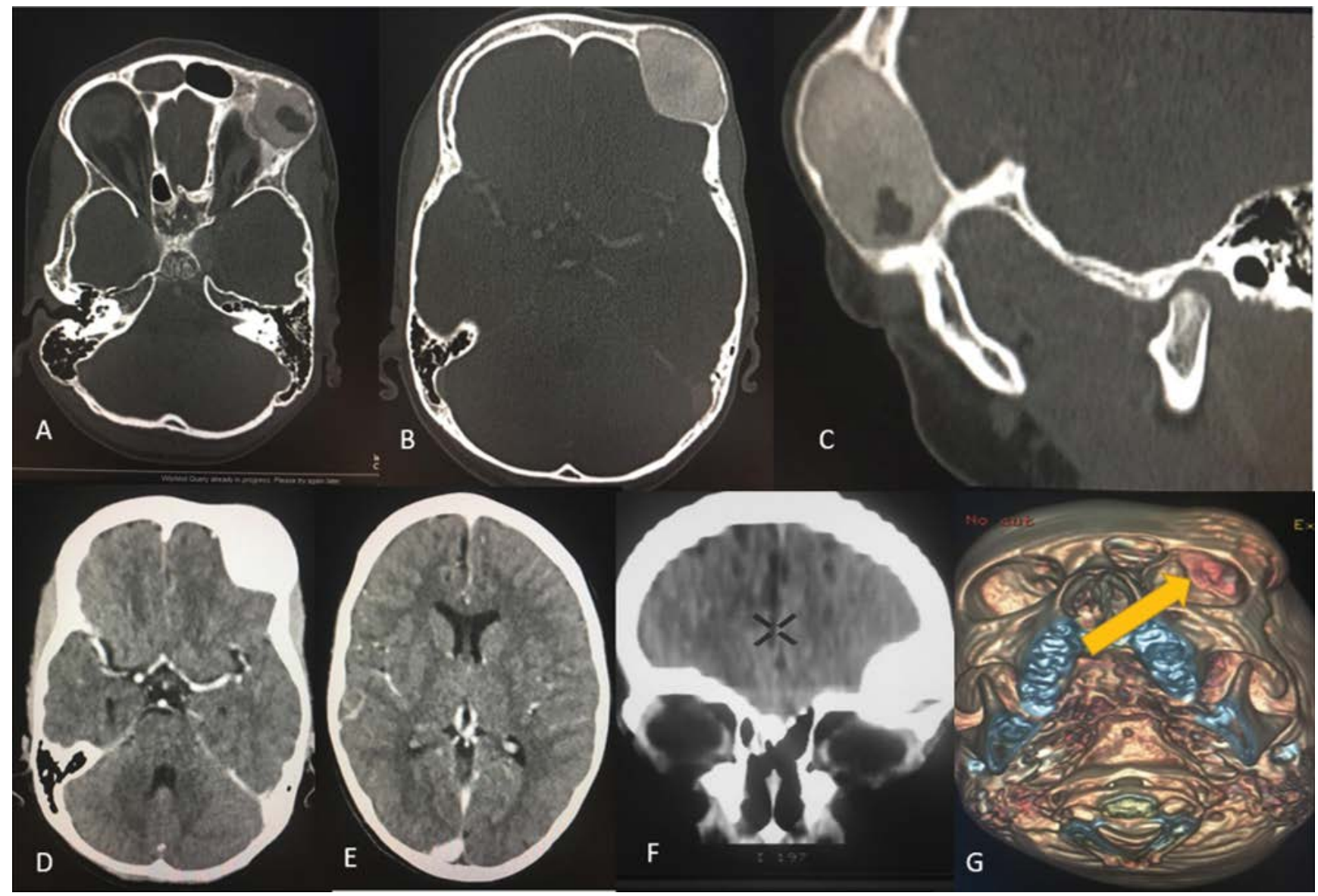

Figure 1: (A,B) Contrasted CT axial; (C) (Sagittal) on bone window; (D,E) (Axial); (F) Coronal reformat on soft tissue window; (G) 3D bone reconstruction. (A) (Lower cut); (B) (Upper cut); (C) Demonstrated an expansile, oval shaped intramedullary non-enhancing osseous lesion in the left frontal bone with a small area hypodensity and inner table thinning; (D,E and $F$ ) Demonstrated a well-defined osseous lesion with no intracranial extension, no obvious mass effect to the brain or intracranial lesion; (G) Demonstrated protuberant bony lesion that abuts upon the orbital roof the left eye.

The child was relatively healthy until the swelling slow but progressively begun to emerge. The reason the mother sought medical help was not because the child felt symptoms but because the swelling was growing larger in size. Past medical and family histories were unremarkable. On clinical exam, there was a non-tender, immobile, bony hard swelling on the left forehead, $1 \mathrm{~cm}$ above the superior bony margin of the orbital rim that measured $3 \times 2 \times 0.5 \mathrm{~cm}$. The overlying skin was normal and mobile over the swelling. The cough impulse and the transillumination tests were negative. There was no other swelling in the body. There was no neurologic deficit of mental status, cranial nerves, motor, sensory, deep tendon reflexes, gait and coordination and the cerebellum.

Contrasted computed tomography (CT) scan of the brain demonstrated a well-defined, expansile, oval shaped, intramedullary non-enhancing osseous lesion in the left frontal bone measured $3.9 \times 2.6 \times 4.0 \mathrm{~cm}$. There was small intra-lesional lytic area. There was thinning of the inner plate of the cortical bone. The lesion abuts upon the orbital roof. There was no periosteal reaction. There was no intra-cranial extension. The overlying soft tissues were normal. There was no intra-conal extension. Both orbits were normal. The cerebrum, cer- ebellum, midbrain, pons and medulla were normal. No satellite lesions noted in the head and the demonstrated upper cervical vertebrae (Figure 1).

Core biopsy was done and the histopathology result revealed primary osteoblastoma of the cranium. Craniotomy of the outer plate of the affected frontal bone was made. Total excision of the lesion was done with great care to the inner plate (Thinning was demonstrated in the CT scan). Firm, red-brownish colored like substance was removed with ease. The inner plate, the orbital roof cortex was intact. The potential space was filled with bone cement and single plate bone flap was placed in situ. The parents and the child were satisfied with the outcome of the surgery.

\section{Discussion}

Osteoblastomas are rare entities which are benign in nature though at times aggressive osteoblastomas can present with recurrence [9]. Osteoblastomas are commonly seen in the second and third decade of life with mean age of 20 [6]. Our patient was only eight-years-old at the time of presentation.

Clinical presentation of osteoblastoma is highly dependent upon tumor location, extension, and mass ef- 
fect, presentation ranges from localized pain to cranial nerve deficits and rare seizures [10]. Symptom onset is typically progressive, with an average duration of 18 24 months prior to presentation [11]. Most commonly they present as subcutaneous swelling with nocturnal pain that usually responds to salicylates $[10,11]$. Our patient's frontal bone swelling was painless.

On computed tomography, calvarial osteoblastoma generally appears as a well-demarcated, mixed-lytic and sclerotic lesion with enlarged diploe, thinning outer and/or inner tables, and varying degrees of calcification [12]. At times soft tissue density can present in a portion of the lesion. It is believed that mostly it has high vascularity, and as a result can enhance [13]. Nonetheless non-enhancing lesions have also been reported $[12,13]$, like in this case. Our patient had a widening diploe with thinning of inner table. The main portion of the lesion was an osseous lesion with central soft tissue density. Since there are differentials that have similar CT appearance like Giant cell tumor and meningioma, it should be supported by histopathology for confident diagnosis as we got in this child [14].

Osteoblastoma can grow and can be aggressive. The differentiation is mainly by histopathology though radiological can show locally aggressive growth which often is greater than $4 \mathrm{~cm}$ [15]. There was no evidence of radiologic and histopathologic aggressiveness in this patient.

The treatment of choice for cranial osteoblastoma is total resection of the mass with free margins as subtotal resection can lead to greater rate of recurrence $[6,16]$. Chemo-radiation is reserved for unresectable lesions in cases of critical neurovascularity or recurrent lesions [16]. Our patient underwent total resection with free margins.

\section{Conclusion}

Cranial osteoblastoma is a rare entity. CT scan plays a big role in the differentiating bone tumors of the calvarium but histopathology determines the definitive diagnosis. Gross total resection is the treatment of choice; as subtotal resection has risk of recurrence.

\section{Declaration}

\section{Ethics approval and consent to participate}

The child's parent provided an informed written consent to participate in the study.

\section{Consent for publication}

The child's parent provided an informed written consent for this case to be published in a peer-reviewed journal.

\section{Availability of data and materials}

The information used and/or analyzed during this case report is available from the corresponding author on reasonable request.

\section{Competing interests}

The authors declare that they have no competing interests.

\section{Funding}

No funding.

\section{Authors' Contribution}

All authors made a significant contribution to the work reported, whether that is in the conception, study design, execution, acquisition of data, analysis and interpretation, or in all these areas; took part in drafting, revising or critically reviewing the article; gave final approval of the version to be published; have agreed on the journal to which the article has been submitted; and agree to be accountable for all aspects of the work.

\section{Acknowledgements}

We would like to acknowledge, the child and his parents, the staffs of radiology and neurosurgical ward, for they actively supported the process of data collection and follows up updates of the patient.

\section{References}

1. Sahu S, Padhiary S, Banerjee R, Ghosh S (2019) Osteoblastoma of mandible: A unique entity. Contemp Clin Dent 10: 402-405

2. Perez-Mora RM, Sanchez-Carrion S, Barea FL, Garcia-Raya P, Lassaletta L (2009) Osteoblastoma of the temporal bone. Skull Base 19: 345-348.

3. Patnaik S, Jyotsnarani Y, Uppin SG, Susarla R (2016) Imaging features of primary tumors of the spine: A pictorial essay. Indian J Radiol Imaging 26: 279-289.

4. Toescu SM, Alalade AF, Steele L, Bhargava D, Hunter R (2017) Frontal skull osteoblastoma with aneurysmal bone cyst-like changes associated with trauma during pregnancy: A case report. Acta Neurochir (Wien) 159: 393-396.

5. Meli GA, Meli L, Chiaramonte R, Riva G, Pero G (2008) Osteoblastoma of the orbit. A case report and review of the literature. Neuroradiol J 21: 71-76.

6. Wu M, Xu K, Xie Y, Yan F, Deng Z, et al. (2019) Diagnostic and management options of osteoblastoma in the spine. Med Sci Monit Int Med J Exp Clin Res 25: 1362-1372.

7. Mangham D (2002) World health organisation classification of tumours: Pathology and genetics of tumours of soft tissue and bone. In: CDM Fletcher, KK Unni, F Mertens, IARC Press. Lyon, France.

8. Nguyen TT, Thelen JC, Bhatt AA (2020) Bone up on spinal osseous lesions: A case review series. Insights Imaging 11: 80.

9. Bokhari K, Hameed MS, Ajmal M, Togoo RA (2012) Benign osteoblastoma involving maxilla: A case report and review of the literature. Case Rep Dent.

10. Figueiredo EG, Vellutini E, Velasco O, Siqueira M, Bougar P (1998) Giant osteoblastoma of temporal bone: Case report. Arq Neuropsiquiatr 56: 292-295. 
11. Miller C, Khan R, Lemole GM Jr, Jacob A (2013) Osteoblastoma of the lateral skull base: Work-up, surgical management, and a review of the literature. J Neurol Surg Rep 74: $37-42$.

12. Gomez CK, Schiffman SR, Bhatt AA (2018) Radiological review of skull lesions. Insights Imaging 9: 857-882.

13. Pelargos $P$, Nagasawa $D$, Ung $N$, Chung $L$, Thill $K$, et al. (2015) Clinical characteristics and diagnostic imaging of cranial osteoblastoma. J Clin Neurosci.
14. Alli A, Johnson $P$, Reeves $A$ (2013) Imaging characteristics of occipital bone osteoblastoma. Case Rep Radiol.

15. Jennin F, Bousson V, Parlier C, Jomaah N, Khanine V, et al. (2011) Bony sequestrum: A radiologic review. Skelet Radiol 40: 963-975.

16. Ugur HC, Torun F, Kanpolat $Y$ (2005) Petrous bone osteoblastoma invading the cavernous sinus. J Clin Neurosci 12: 489-492. 